\title{
A Comercialização de Produtos em Lã Natural como Souvenir: Manutenção da Identidade Cultural de Jaguarão/RS
}

\section{La Comercialización de Productos en Lana Natural como Souvenir: Mantenimiento de la Identidad Cultural de Jaguarão / RS}

\section{The Commercialization of Natural Wool Products as Souvenir: Maintenance of the Cultural Identity of Jaguarão / RS}

\author{
Helora Ataydes Dilelio Ávila ${ }^{1}$ \\ Alessandra Buriol Farinha ${ }^{2}$
}

\begin{abstract}
Resumo
Os pampas gaúchos, dotados de uma forte identidade rural, são responsáveis pela maior produção lanífera do país, fazendo assim surgir técnicas específicas de seu aproveitamento como matéria-prima. O estudo busca demonstrar a comercialização de souvenirs em lã natural como forma de manutenção da identidade rural do município de Jaguarão/RS, localizado no extremo sul do Rio Grande do Sul e fronteira com Rio Branco Uruguai. Assim, procura-se analisar a constituição da tecelagem em lã natural como herança cultural da região, verificar a viabilidade de sua comercialização como souvenir e evidenciar a afirmação da identidade rural através da confecção das peças. Empregou-se, na metodologia, pesquisa bibliográfica e de campo, com entrevistas semiestruturadas junto à grupos de artesãs em lã natural, vinculados à Associação Municipal dos Artesãos e Economia Solidária, e com a Cooperativa de Lãs Mauá. A análise das entrevistas permitiu identificar sua relevância na constituição da identidade cultural e rural do município, bem como a possibilidade do uso das peças como souvenir de forma a preservar os aspectos culturais dos autóctones, incluindo-os no círculo econômico do turismo. Devido à preocupação com a preservação dos aspectos culturais, considera-se viável a produção e comercialização de peças junto ao setor turístico, permitindo a visibilidade, valorização e manutenção de sua identidade, agindo ainda como propulsor do turismo e vetor socioeconômico para os moradores locais.
\end{abstract}

Palavras-Chave: tecelagem; turismo; identidade rural; herança cultural; souvenir.

\section{Resumen}

Las pampas gauchas, dotadas de una fuerte identidad rural, son responsables de la mayor producción lanífera del país, haciendo así surgir técnicas específicas de su aprovechamiento como materia prima. El estudio busca demostrar la comercialización de souvenirs en lana natural como forma de mantenimiento de la identidad rural del municipio de Jaguarão / RS, ubicado en el extremo sur de Rio Grande do Sul y frontera con Rio Branco Uruguay. Así, se busca analizar la constitución del tejido en lana natural como herencia cultural de la región, verificar la viabilidad de su comercialización como souvenir y evidenciar la afirmación de la identidad rural a través de la confección de las piezas. Se empleó, en la metodología, investigación bibliográfica y de campo, con entrevistas semiestructuradas junto a grupos de artesanas en lana natural, vinculados a la Asociación Municipal de los Artesanos y Economía Solidaria, y con la Cooperativa de Lãs Mauá. El análisis de las entrevistas permitió identificar su relevancia en la constitución de la identidad cultural y rural del municipio, así como la posibilidad del uso de las piezas como souvenir para preservar los aspectos culturales de los autóctonos, incluidos en el círculo económico del turismo. Debido a la preocupación por la preservación de los aspectos culturales, se considera viable la producción y comercialización de piezas junto al sector turístico, permitiendo la visibilidad, valorización y mantenimiento de su identidad, actuando como propulsor del turismo y vector socioeconómico para los habitantes locales.

1 (Graduanda em Gestão de Turismo; Universidade Federal do Pampa - Unipampa; Jaguarão, Rio Grande do Sul, Brasil; heloradilelio@gmail,com).

2 (Doutora em Memória Social e Patrimônio Cultural; Universidade Federal do Pampa - Unipampa; Jaguarão, Rio Grande do Sul, Brasil; alefarinha@yahoo.com.br). 
Palabras claves: tejer; turismo; identidad rural; herencia cultural; recuerdo.

\begin{abstract}
The pampas gauchos, endowed with a strong rural identity, are responsible for the country's largest wool production, thus creating specific techniques for its use as raw material. The study seeks to demonstrate the commercialization of souvenirs in natural wool as a way of maintaining the rural identity of the municipality of Jaguarão / RS, located in the southernmost part of Rio Grande do Sul and bordering Rio Branco - Uruguay. Thus, we seek to analyze the constitution of natural wool weaving as a cultural heritage of the region, verify the viability of its commercialization as souvenir and evidence the affirmation of rural identity through the making of the pieces. In the methodology, bibliographical and field research was used, with semi-structured interviews with natural wool artisan groups, linked to the Municipal Association of Artisans and Solidary Economy, and with the Cooperativa de Lãs Mauá. The analysis of the interviews allowed to identify their relevance in the constitution of the cultural and rural identity of the municipality, as well as the possibility of using the pieces as souvenirs in order to preserve the cultural aspects of the native people, including them in the economic circle of tourism. Due to the concern with the preservation of cultural aspects, it is considered viable the production and sale of pieces in the tourism sector, allowing the visibility, valorization and maintenance of its identity, acting as a propeller of tourism and socioeconomic vector for local residents.
\end{abstract}

Keywords: weaving; tourism; rural identity; cultural heritage; souvenir.

\title{
1. Introdução
}

Os fazeres e saberes do meio rural constituem características influentes na composição da bagagem cultural do Rio Grande do Sul. A atividade pecuária, sendo importante vetor econômico, constitui parte da identidade gaúcha, ao qual está associada à lida campeira, aspecto indissociável do perfil traçado sobre a figura do sul-riograndense.

No Rio Grande do Sul, responsável por 91,4\% da produção de lã nacional (IBGE, 2016), a ovinocultura teve sua origem vinculada à vinda dos espanhóis para a região do Rio da Prata, que divide os países Uruguai e Argentina, espalhando-se para o estado, através dos anos, devido às proximidades entre suas características geográficas. A tecelagem, já utilizada pelos povos indígenas, sofreu modificações ao entrar em contato com os fluxos culturais de outras etnias ao longo dos anos. Desde a vinda dos jesuítas, trazendo os primeiros teares e a chegada dos imigrantes europeus, até o próprio convívio com países vizinhos nas áreas de fronteiras contribuíram para a formação das técnicas de tecelagem atuais.

A criação de ovinos para tosquia em Jaguarão, município situado no extremo sul do estado do Rio Grande do Sul, integrante dos pampas sulinos e fronteira com o município de Rio Branco no Uruguai, destaca-se no estado, tendo apresentando uma produção média de 127 mil quilos de lã no ano de 2017 (IBGE, 2017).

Desse modo, a produção lanífera e a tecelagem constituem-se aspectos culturais do município, representando a identidade rural da população local. A preocupação com a manutenção de tais características leva os moradores das zonas rurais de Jaguarão à recusa da prática de atividades turísticas em suas propriedades. 
A pesquisa tem como principal objetivo demonstrar a comercialização de souvenirs em lã natural como forma de manutenção da identidade rural do município de Jaguarão/RS. Assim, procura-se analisar a constituição da tecelagem em lã natural como herança cultural da região, verificar a viabilidade de sua comercialização como souvenir e evidenciar a firmação da identidade rural através da confecção das peças.

A metodologia empregada foi uma revisão bibliográfica em meios físico e virtual. Realizaram-se entrevistas junto à duas integrantes do grupo de artesãs "As Cardadeiras", vinculado à economia solidária, à cinco artesãs da Associação Municipal dos Artesãos e ao presidente da Cooperativa de Lãs Mauá. Foi feita observação de campo sobre a produção de peças e durante a realização do curso de Jacquard, ministrado na sede da associação. A importância da pesquisa a campo para Gil (2008, p. 57), se dá da seguinte maneira: “Como consequência, o planejamento do estudo de campo apresenta uma maior flexibilidade, podendo ocorrer mesmo que seus objetivos sejam reformulados ao longo do processo de pesquisa”.

\section{Contextualização: a tecelagem no Rio Grande do Sul}

A ovinocultura foi introduzida no Rio Grande do Sul através da chegada de espanhóis, que trouxeram os primeiros rebanhos para povoar a região do Rio da Prata, que eram criados livres no campo e sem assistência humana (VIANA; WAQUIL; SPOHR, 2010). Esse fator tende a sugerir uma razão pela qual a produção lanífera se desenvolveu principalmente nas cidades próximas às fronteiras.

Durante a primeira guerra mundial, a procura pela lã aumentou em função de uso em materiais bélicos, fazendo com que países europeus passassem a importá-la da Argentina e Uruguai, em locais próximos à fronteira com o Rio Grande do Sul, que por sua vez, revendia sua produção ao Uruguai (OLIVEIRA, 2012). A produção de lã cresceu consideravelmente até os anos de 1960, atuando como maior riqueza da fronteira. Denominada "Ouro branco", compunha o quadro das exportações mais importantes do estado (BOFILL apud. VIANA; WAQUIL; SPOHR, 2010).

Nas décadas seguintes, o plantio de arroz e a soja, cujo rendimento econômico era $50 \%$ maior, acarretou na diminuição das terras que antes se destinavam à criação de ovinos. (OLIVEIRA, 2012). Desse modo, para permanência da ovinocultura, os gaúchos começaram a investir em raças de ovinos de duplo propósito (carne e lã), passando a comercializar uma quantidade maior de carne ao invés de lã. (VIANA; WAQUIL; SPOHR, 2010). Ainda assim, 
o panorama atual da produção lanífera no Rio Grande do Sul passa pela reestruturação e o mercado volta a se reestruturar.

Diante de uma identidade rural constituída, em parte, pela utilização da lã como matéria prima, surgiram no estado técnicas para seu aproveitamento, a qual destaca-se a tecelagem. Sua origem no Rio Grande do Sul provém do período colonial. Trançando fibras e algodão, as mulheres indígenas habitantes da região já confeccionavam tecidos a partir da tecelagem. Com a chegada dos Jesuítas, por volta do século XVII, foram introduzidos os primeiros teares, ensinando a técnica da tecelagem também em lã ovina. Tal prática, exercida apenas pelas mulheres, permitia a confecção de peças de vestuário e de utilização doméstica, cujo pouco excedente era comercializado nas cidades de Porto Alegre e Rio Grande. (CASTRO; BECKER; EGGERT, 2010).

Os autores afirmam que, com a chegada dos primeiros imigrantes alemães e italianos no estado, que exerciam ofícios artesanais, as produções, inicialmente domésticas, foram expandidas ao nível comercial. Aos poucos, começou a se originar a indústria têxtil gaúcha. $\mathrm{O}$ município de Jaguarão, ao qual se aplica a pesquisa, está localizado no bioma pampa, Rio Grande do Sul, fazendo fronteira com Rio Branco, no departamento de Cerro Largo, Uruguai. Apresenta uma população de aproximadamente 28 mil habitantes (IBGE, 2010) e possui, segundo resultados preliminares de pesquisas realizadas em 2017 pelo Instituto Brasileiro de Geografia e Estatística (IBGE), 199.115,814 hectares destinados a estabelecimentos agropecuários.

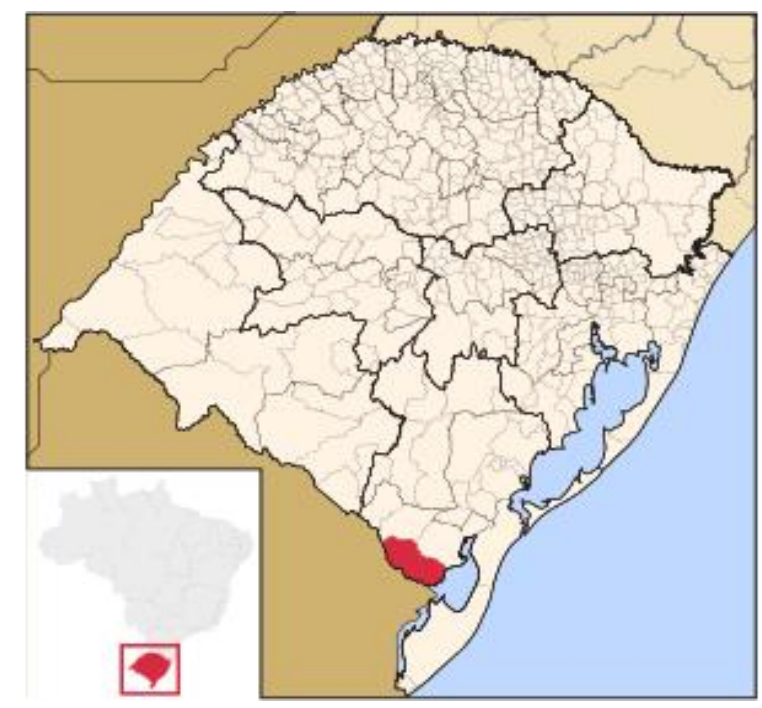

Figura 1 - Mapa de localização de Jaguarão no Rio Grande do Sul.

Fonte: Abreu (2006). 
Com um rebanho de aproximadamente 53 mil ovinos, a produção lanífera de Jaguarão, $20^{\mathrm{a}}$ maior do estado, alcançando uma quantidade de $127.647 \mathrm{~kg}$ de lã no último ano (IBGE, 2017). A criação de ovinos, como atividade pecuária comum no município, resulta na disponibilidade de matéria-prima, de forma a também ser utilizada na confecção de peças por tecelagem.

Sem auxílio de máquinas industriais e aditivos químicos, as artesãs jaguarenses realizam uma técnica que se inicia a partir do trabalho com o velo da ovelha, ao qual a lã é lavada, secada, aberta, cardada, fiada e tingida com elementos naturais, como erva-mate, casca de cebola, marcela e beterraba. Por fim, confeccionam-se as peças com a técnica de tecelagem e crochê Jacquard, realizadas manualmente ou em teares.

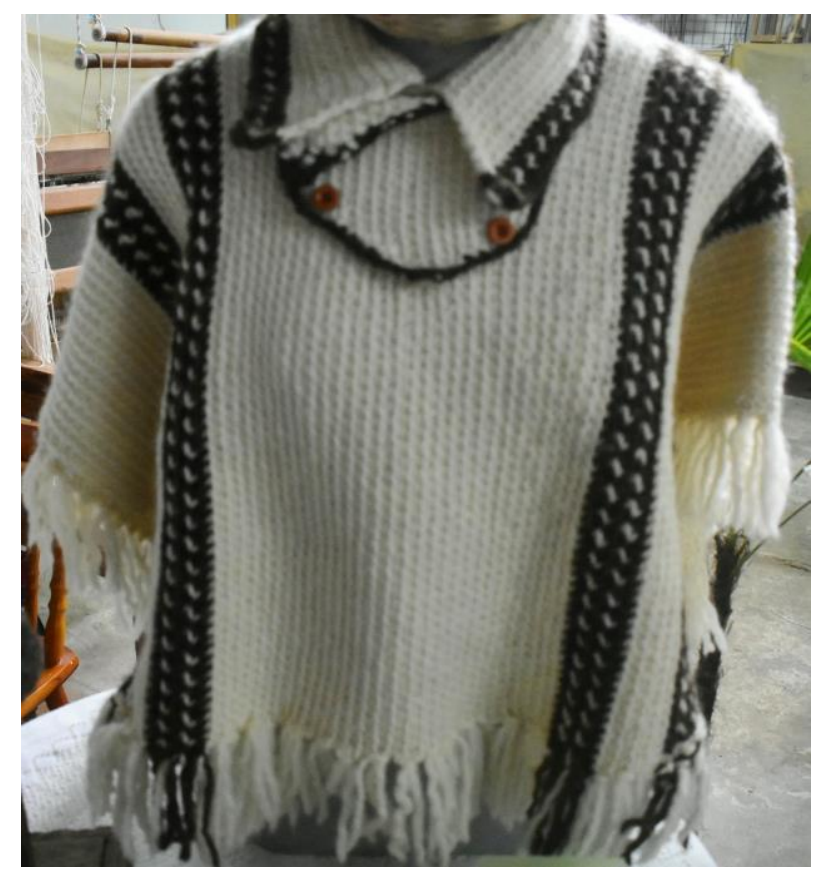

Figura 2 - Poncho confeccionado em Jacquard pela Associação Municipal de Artesãos.

Fonte: Acervo da autora (2018).

\section{Concepções Teóricas}

Para melhor compreensão dos assuntos abordados no estudo, serão apresentados à seguir, reflexões teóricas sobre os aspectos que tangem a tecelagem em lã natural. Inicialmente, serão apresentados conceitos sobre memória e identidade, caracterizando, assim, a tecelagem em lã natural, uma prática cultural.

No tópico seguinte, irá discorrer sobre a relação da atividade turística com a população local e sua influência sobre o conjunto cultural do destino. Assim, buscará traçar os aspectos 
que influenciam negativa e positivamente a manutenção da identidade dos autóctones. Posteriormente, irá discutir as concepções sobre souvenir e cultura, de modo a identificar as potencialidades socioeconômicas e de manutenção dos bens culturais através da comercialização das peças em lã natural.

\subsection{Tecelagem: Cultura e Identidade}

A tecelagem, compreendida como uma representação da cultura campeira da região, tem sua técnica de confecção no município iniciada a partir do preparo da lã, passando pelo planejamento das peças, elaboração e finalização das mesmas. Expressando a identidade rural, é um saber transmitido pela memória geracional, familiar, entre mulheres do campo. São as características históricas, sociais, geográficas que vão moldar, caracterizar os costumes, as tradições locais, e também a memória e o patrimônio da comunidade. A construção da identidade está diretamente vinculada à interpretação das memórias.

Se identidade, memória e patrimônio são 'as três palavras-chave da consciência contemporânea' - poderíamos, aliás, reduzir a duas se admitimos que o patrimônio é uma dimensão da memória -, é a memória, podemos afirmar, que vem fortalecer a identidade, tanto no nível individual quanto no coletivo: assim, restituir a memória desaparecida de uma pessoa é restituir sua identidade (CANDAU, 2011, p. 16).

De acordo com o autor, sobre a relação entre memória e identidade, é possível compreender que ambas são indissociáveis, uma vez que "Não há busca identitária sem memória e, inversamente, a busca memorial é sempre acompanhada de um sentimento de identidade, pelo menos individualmente" (CANDAU, 2011, p. 19). Sobre a criação de memórias coletivas, o autor cita ainda:

Não pode haver construção de uma memória coletiva se as memórias individuais não se abrem umas às outras visando objetivos comuns, tendo um mesmo horizonte de ação. Isso é evidentemente mais fácil em grupos menores, como, por exemplo, as famílias. (CANDAU, 2011, P. 48).

Através do compartilhamento de memórias, a construção de identidades coletivas incide na expressão cultural dos grupos. Difundidas de geração em geração, as heranças culturais proporcionadas pelos fazeres do campo, representam ainda hoje uma memória coletiva, que promove a afirmação identitária dos moradores da zona rural do município, enfatizando os aspectos principais de sua formação social e cultural. 
Candau (2011) lembra ainda que o compartilhamento da memória individual na construção da coletiva permite sua reestruturação e modificação através dos acréscimos, seleções e eliminações estabelecidas em conjunto. Assim, a memória, que em seu estado pessoal apresenta singularidades próprias, forja-se, em seu viés coletivo, da compilação e adaptação de todas essas especificidades. A tecelagem, partilhada ao longo das gerações, apresenta várias versões resultantes das adaptações e incrementação de especificidades. Nos grupos de artesãs, a construção de uma memória coletiva a partir das heranças individuais moldaram sua aplicação atual.

O sociólogo Raymond Williams (2011) aborda o conceito de cultura apresentando suas três dimensões: antropológica, sociológica e estética. No contexto antropológico, a visão geral de cultura, valorada por atividades intelectuais e elitistas, é quebrada. O conceito está diretamente relacionado ao "modo de vida" e todos os fazeres e saberes do homem, o que nega sua redução à puramente artística, e estende a equivalência do conceito a toda diversidade étnica e social em seus particularismos.

Como prática realizada nos meios rurais jaguarenses, a tecelagem teve sua formação através da transferência de saberes. Ensinada ao longo das gerações, carrega os conhecimentos antigos sobre atividades campeiras, caracterizando seu modo de vida. Salvaguardada pela visão antropológica, a confecção das peças, inicialmente vista como um simples ofício doméstico feminino, sem qualquer relevância cultural, passa a ser englobada pelo conceito.

Na visão sociológica, cultura refere-se à produção e o consumo de atividades culturais pelo qual se conhecem os grupos sociais. Essa interpretação do conceito traz a perspectiva de comercialização e de indústria cultural, passando esta a ser considerada como um bem de consumo. A sociologia percebe o conceito de cultura como o "sistema de significações mediante o qual necessariamente (se bem que entre outros meios) uma dada ordem social é comunicada, reproduzida, vivenciada e estudada" (WILLIAMS, 2011, p. 13). A cultura adquire assim um valor de expressão e contato entre aquele que a produz e aqueles que a contemplam.

Não apenas pela comercialização, o artesanato em lã natural representa uma ferramenta de conhecimento e análise de grupos sociais. Sua confecção reflete em si as conquistas alcançadas por suas artesãs ao longo dos anos de sua criação, bem como abriga marcas dos fluxos culturais a qual agregou a partir do contato com outros povos. Já na sua utilização estética, está relacionado às Belas Artes, como pintura, música, teatro, entre outros; trazendo, ao conceito, a expressão do criador na obra criada. 
Cultura pode ser entendida ainda como estética, que apesar da ligação com a tecelagem não ser explícita, os aspectos da moda, o desenho das peças, a montagem da composição de cores e mesmo o próprio fazer artesanal denotam relações com o conceito, permitindo, principalmente, a expressão da artesã através da confecção.

[...] há certa convergência entre os sentidos antropológico e sociológico de cultura como 'modo de vida global' distinto, dentro do qual percebe-se, hoje, um 'sistema de significações' bem definido não só como essencial, mas como essencialmente envolvido em todas as formas de atividade social, e o sentido mais especializado, ainda que também mais comum, de cultura como 'atividades artísticas e intelectuais'[...] (WILLIAMS, 2011, p. 13).

De um lado (sociológico e antropológico), o conceito de cultura estabelece a compreensão dos diferentes estilos de vida e sua expressão através de fazeres e saberes, envolvendo, assim, toda forma sociável, caracterizado pelo coletivo de um grupo. De outro (estético), apresenta-se como puramente ligada às artes e ao intelecto, embora atualmente, contemplando também todos os fazeres considerados significativos, que envolvem desde a filosofia, até mesmo, a moda e a publicidade.

\subsection{Turismo: Relações com a Identidade Local}

Como fenômeno social, o turismo provoca modificações onde se desenvolve. Os impactos, sejam positivos ou negativos, tangem tanto o meio ambiente, quanto aspectos sociais e culturais. Apesar dos benefícios identificados na economia local, as consequências derivadas dessas atividades demonstram a necessidade de analisar formas sustentáveis de inserir a população local no setor minimizando os riscos da mercantilização da cultura como produto turístico.

O turismo é uma atividade que, como qualquer outra, desencadeia mudanças e transformações no local em que se desenvolve, principalmente quando se considera a mesma como um fenômeno social, de contato intercultural. O desenvolvimento do processo turístico desencadeará impactos de natureza positiva e negativa com implicações sinérgicas espaço temporais, que recairá sobre o homem, a sociedade e o entorno natural. (PIRES apud. SILVA e SANT'ANA, 2014, p. 659)

Como ressalta o autor, o turismo causa efeitos e transformações onde é desenvolvido, derivados do contato social e cultural entre turistas e autóctones. Dessa forma, sempre manifestará impactos de diferentes naturezas onde se desenvolve.

Em sua análise sobre os impactos do turismo nas comunidades receptoras, Krippendorf (2009) demonstra que, apesar dos benefícios econômicos da atividade turística, 
há sempre repercussões de cunho social, cultural e ambiental. Tais aspectos podem ocasionar mudanças negativas no modo de vida local e na ameaça à identidade cultural, além de prejuízos ecológicos.

Especificamente nos exemplos de desenvolvimento do turismo no meio rural, tema aqui abordado, o autor reflete ainda que nem sempre a implantação de rotas e atrativos é condizente com a vontade da comunidade rural, cuja apenas pequenos números de pessoas conseguem participar de forma mais ampla. "Estes últimos nunca puderam participar na qualidade de parceiros de fato; com exceção de uma pequena minoria: os mais espertos, os mais hábeis, a nata." (KRIPPENDORF, 2009, p. 71).

No caso da zona rural de Jaguarão, é perceptível a resistência dos moradores em trabalhar com o setor turístico. O receio é justificado, por vezes, com a preocupação em manter suas tradições e identidade longe das ameaças retratadas pelo contato com o turista, e consequentemente, diferentes culturas, e a comercialização de seu modo de vida.

O autor cita ainda duas problemáticas que devem ser analisadas, a respeito do desenvolvimento turístico. A partir da expansão do setor, há certa tendência de declínio de outras atividades econômicas, tornando o destino refém dos turistas e de suas próprias condições econômicas. "o crescimento do perigo de crise que a economia local enfrenta quando a rápida expansão do turismo provoca o declínio da agricultura e carrega em seu bojo todas as outras atividades econômicas, resultando, finalmente, numa monocultura turística bastante frágil [...]" (KRIPPENDORF, 2009, p. 78-79).

Outra problematização traçada pelo autor está relacionada à cultura e os costumes dos moradores locais. Observa-se os impactos negativos causados pelo turismo na vida pessoal da comunidade. "[...] o declínio cultural causado pela adaptação ao gosto estrangeiro, a comercialização do folclore e a prostituição cultural” (KRIPPENDORF, 2009, p. 79).

Dessa forma, percebe-se que o turismo de fato impacta diretamente a identidade local. Além de gerar consequências em diferentes aspectos, atinge, principalmente, a bagagem cultural dos moradores que pode ser descaracterizada, incluindo seu modo de vida, fazeres e saberes, como suas próprias atividades econômicas já alicerçadas.

A transformação do destino em turístico segue os padrões impostos pelo mercado, adequando-se ao gosto do turista. Conforme Banducci Júnior e Barreto, (2006, p. 18) "o processo de turistificação (transformação em lugar turístico) dá-se ao sabor do mercado, de empreendedores isolados, quase sempre sem planejamento. Formam-se estereótipos. Tudo é movimento". 
A adaptação da comunidade local para a recepção de turistas interfere diretamente em seu modo de vida, que, por sua vez, resulta em uma modificação cultural e identitária. Os autóctones passam a reproduzir suas tradições e costumes de forma mercantilizada, o que pode levar a desconstrução de seus significados e de sua importância no cotidiano dos grupos.

Do mesmo modo, o contato com etnias diferentes pode levar à desestruturação de sua própria bagagem cultural e desestabilizar sua constituição social. "Isso tudo somado à aculturação e à miscigenação - ou seja, a transferência de cargas e valores culturais e a mescla deles entre grupos diferentes -, pode dar início à modificação e perda das tradições." (PANOSSO NETTO, 2013, p. 94).

Ainda assim, também é importante citar os aspectos positivos resultantes do turismo para a cultura e identidade local. Tanto a valorização do modo de vida da comunidade, que eleva sua autoestima e o autoconhecimento de sua bagagem cultural, possibilitando a fortificação de sua identidade, quanto o revigoramento das memórias por parte dos próprios moradores locais, que apoderam-se novamente de suas tradições e costumes.

Os modos de vida, as danças, as línguas e costumes também se beneficiam do turismo, pois ao mostrar sua cultura, esses povos podem sentir-se valorizados e perceber que seu modo de vida é diferente, único, e por isso mesmo deve ser preservado. Essa valorização cultural pode originar programas de preservação, orgulhando os envolvidos e elevando a sua autoestima. (PANOSSO NETTO, 2013, p. 91).

Dessa forma, o turismo atua como um fortalecedor da identidade cultural do destino, proporcionando a manutenção de seus bens e de seu modo de vida, valorizando-os, tanto perante ao turista, quanto ao morador local, que é tomado pelo sentimento de pertencimento. Assim, as memórias são "revitalizadas" e a bagagem cultural pode ser ressignificada e novamente incluir-se no modo de vida da comunidade.

O turismo passa, nesse caso, a ser um dos fatores que desencadeiam o processo de aproximação entre passado e presente. Inicialmente visto como cultura encenada, como tradição inventada para o consumo turístico, acaba penetrando os interstícios do tecido social e transformando-se em movimento cultural do presente com interesse genuíno na valorização e no conhecimento do próprio passado. (BADUCCI JÚNIOR; BARRETO, 2006, p. 16).

As peças confeccionadas a partir da tecelagem em lã natural, bem cultural e memória de Jaguarão, quando comercializadas junto aos fluxos turísticos, permitem a reafirmação de sua identidade. Ao permanecer no cotidiano dos artesãos como fonte de renda, a técnica é ressignificada individualmente, e seu produto, como manifestação material dessa memória, recebe o reconhecimento mediante os turistas, resultando na elevação da autoestima dos 
autóctones, através da visibilidade de algumas de suas características culturais, impressas nas tramas da peça.

Percebe-se assim, a necessidade de balancear os impactos negativos do setor turístico com a ampliação dos positivos. Conforme Banducci Júnior e Barreto (2006, p. 42), “O turismo, como agente desse processo amplo, pode tanto destruir como estimular respostas positivas que venham reforçar a identidade do grupo ou outros aspectos da cultura local”.

Desse modo, de forma geral, pode-se considerar que o turismo, como uma atividade que tange diversos aspectos do destino em que se desenvolve, quando aplicado de forma sustentável, beneficia a comunidade receptora. Entretanto é necessária a busca por medidas capazes de conter seus danos e preservar os autóctones das consequências nocivas da exploração turística e da mercantilização de seu modo de vida.

\subsection{Souvenir: Possibilidade de Desenvolvimento e Manutenção Cultural}

As concepções acerca do termo ainda mostram-se restritas pela escassez de estudos a seu respeito. Utiliza-se, aqui, a ideia de souvenir como símbolo para evocação de memórias, que materializa a experiência e desperta o interesse dos turistas. Assim, ele pode ser entendido como uma forma de representar a relação do turista com o destino visitado de maneira tangível. "La comercialización de los recuerdos representa diferentes memorias de distintas personas en una sociedad de consumo en donde se intenta mediante un producto reproducir una experiencia [...]" (ESCALONA, 2006, p. 402).

As ideias formadas de souvenir na contemporaneidade são abordadas por De Paula e Mecca (2016), que percebe, nessa perspectiva, o acréscimo de significado, relacionando-o ao artesanato. "O modelo artesanal encontrado nos souvenirs de hoje apresenta características territoriais que valorizam a cultura de determinada comunidade, contribuindo, também, para o desenvolvimento local, por meio dos postos de trabalho proporcionados por esta produção." (DE PAULA; MECCA, 2016, p. 387).

Dessa forma, o desenvolvimento de peças através de técnicas artesanais que integram a bagagem cultural dos moradores em um destino como souvenir representa também uma maneira de contribuir para sua elevação socioeconômica e manutenção de sua cultura. Seja pela geração de renda e de empregos motivada pela comercialização, seja pela valorização cultural do artesanato, o souvenir é uma possibilidade de inserir os artesãos no circulo econômico do turismo de forma menos agressiva.

Como ressalta Escalona (2006, p. 403), 
La producción de souvenirs mantiene técnicas artesanales, proporciona puestos de trabajo en la distribución y venta de los mismos, balanceándose con frecuencia entre la economía formal y la sumergida, y contribuye a la formación de una imagen en el exterior, que intenta ser competitiva en un mundo globalizado, ya que es la prueba tangible del viaje del turista. En esa producción se funde lo local, materiales, habilidades, valores y gusto, con la necesidad de adaptación al comprador y a la influencia exterior. Las coloristas telas urdidas con el telar de cintura maya son un buen diseño para fundas de teléfonos móviles, y se comercializan en los cestos sobre la cabeza de niñas en la ciudad de Antigua y en las muy cuidadas tiendas para turistas.

Percebe-se, assim, que a comercialização do souvenir não apenas proporciona a geração de renda para o artesão que o produz, como também promove sua distribuição de forma mais homogênea no destino. A circulação de capital atinge também os distribuidores e os fornecedores de matéria-prima, acompanhando tanto a economia formal quanto a submergida. Até mesmo pela permanência do capital no destino, uma vez que será utilizado pelos artesãos locais, nota-se a contribuição de sua comercialização para a economia local.

A relação entre cultura e souvenir é geralmente percebida pelos estudiosos do tema como negativa, que apontam a descaracterização ou a mercantilização cultural através das peças comercializadas. (HORODYSKI, MANOSSO, GÂNDARA, 2014). Entretanto, percebe-se a valorização cultural através de sua venda, tanto por parte do turista, que descobre as impressões culturais do destino nas peças, quanto pela própria população local, que da mesma forma, reconhece sua bagagem cultural e lhe atribui novos sentidos.

Ademais, o souvenir é percebido também como uma estratégia de marketing, onde o próprio destino recebe maior visibilidade, impactando diretamente na formação de sua imagem. "O turismo é uma alternativa para integrar os produtos e os serviços locais em atividades que renovem a imagem da comunidade local, melhorando a vida de seus residentes, bem como atraindo turistas." (KRUCKEN apud. DE PAULA; MECCA, 2016, p. 389).

Considerando-se a comercialização de peças confeccionadas em lã natural no município de Jaguarão como souvenir, destaca-se os aspectos híbridos da fronteira Jaguarão/Rio Branco, que configuram uma fonte cultural e são expressados através da técnica. Entretanto, pela falta de visibilidade e articulação dos artesãos na comercialização do souvenir, tais características são desconhecidas pelos turistas. Assim, o fluxo turístico nos municípios tem como foco turístico principal o segmento de compras, em vez dos aspectos culturais oferecidos pela fronteira, cujo atrativo reconhecido pelos turistas são os free shops ${ }^{3}$.

\footnotetext{
${ }^{3}$ Lojas que vendem produtos importados livres de impostos. A maior parte dos turistas que visitam Jaguarão tem como principal objetivo usufruir do turismo de compras nesta fronteira.
} 
Ao estabelecer os contornos de uma paisagem cultural, a outorga de valor patrimonial nacional favorece o aproveitamento desta área para o desenvolvimento da atividade turística em outras dimensões, ultrapassando a dimensão econômico do turismo de compras que caracteriza de modo geral as cidades de fronteira BrasilUruguai. A certificação apresenta ainda como potencialidade a valorização da cultura local, assim como os sujeitos responsáveis pelos saberes e fazeres e pela configuração da paisagem chancelada, estimulando a relação harmoniosa homemmeio (COSTA e GASTAL, 2010, p. 13).

Entende-se, neste contexto, que ampliar a visibilidade da técnica, como bem cultural da cidade, na forma de souvenir, pode contribuir para a valorização e a identificação dos autóctones e seu modo de vida, sua memória, sua identidade. A riqueza histórica impressa na confecção das peças permite maior conhecimento sobre a formação étnica da população e sua identidade, sendo assim a herança de uma memória a qual se deve manter viva.

\section{Souvenir em lã natural como forma de manutenção da identidade cultural}

Segundo relatos durante a entrevista na Cooperativa de Lãs Mauá, a produção de lã como um aspecto da formação da identidade cultural do município ficou ainda mais evidente:

A lã ela tem uma identidade cultural muito forte na origem das famílias do Rio Grande do Sul, especialmente de Jaguarão. Jaguarão, Livramento, toda essa região aqui da campanha. Porque antigamente, se vai ver, a lã surge mais ou menos lá no início do século XX, aqui. E eu lembro assim de dados, de memória, que lá em 1870 o Rio Grande do Sul tinha em torno de 27.000 ovinos no estado todo, então isso não é nada. Lá pela década de 1900 ela começa a se expandir. (Presidente da Cooperativa de Lãs Mauá, entrevistado no dia 17 de setembro de 2018).

A produção lanífera no Rio Grande do Sul representa um dos pilares no qual o gaúcho construiu sua identidade. As regiões de campanha, e em especial de fronteira, devido à colonização hispânica, tem seus laços com a atividade ainda mais engessados, uma vez que foram os primeiros a receberem os rebanhos de ovinos, e também pela proximidade com o Uruguai, que influenciou as tecnologias da produção gaúcha.

Tal aspecto passou a fazer parte do modo de vida nas regiões da campanha do Rio Grande do Sul. Considerando a abordagem de Candau (2011) sobre o conceito de memória e identidade, anteriormente apresentados, pode-se constatar que a criação de ovinos constitui-se de uma memória, transmitida por várias gerações nas zonas citadas, e, consequentemente, parte da identidade local. 
Creio que lá para a década de 1940 e 1950 [...] e a lã nessa época valia muito. De tal forma que as pessoas viviam da lã. Elas produziam a lã anual, mandavam para a Cooperativa, essa lã era classificada aqui e a cooperativa tinha supermercado, bazar, loja de roupas, tudo era adquirido aqui. [...] Então a tradição, a ligação cultural dos filhos da geração que hoje estaria em torno de 50 ou 60 anos, foi uma geração que viveu isso aqui, ligada à cooperativa. Não só a nossa, como ligada à Pelotas, a Bagé, onde tinha cooperativa, era essa a ligação que existia entre a área rural. Então é muito forte. E isso aí foi perdendo a identidade um pouco, mas como toda coisa cíclica, ela perde e volta, e hoje a lã está voltando [...]. (Presidente da Cooperativa de Lãs Mauá, entrevistado no dia 17 de setembro de 2018).

Para os moradores da zona rural jaguarense, a presença da Cooperativa de Lãs correspondia um marco, onde ocorriam as interações com a zona urbana, mantinham as relações sociais e efetuavam as trocas comerciais de sua produção, abastecendo-se com os lucros de seu fruto. Como suporte para os membros, a cooperativa representava ainda um vetor da criação de ovelhas no município, dando o suporte para seu crescimento.

Iniciando ainda no começo do século XX no município, segundo o entrevistado, tal atividade proporcionou uma vasta disposição de matéria prima, a lã, ao qual se agregaram técnicas e práticas de tecelagem, como o próprio Jacquard, para seu aproveitamento. Dessa forma, o excedente da produção passou a ser trabalhado pelas mulheres dos ovinocultores na confecção de peças de vestuário e de necessidade domiciliar.

A gente já se criou com uma ovelhinha embaixo do braço e aí isso vai indo assim, continua, e a gente já se acostumou a trabalhar com a lã desde pequena, que a mãe e as avós já trabalhavam e isso vai passando assim, é bem interessante. (C.R.D., Integrante do grupo As Cardadeiras, vinculado à economia solidária, entrevistada no dia 13 de setembro de 2018).

Assim, a tecelagem com lã natural, como uma memória das mulheres artesãs, transmitida de geração à geração, de fato representa uma herança cultural do município, uma vez que, só pelo fato de se tratar de um saber, o que antropologicamente configura-se como cultura, já pode ser visualizado como um patrimônio herdado pelas mulheres artesãs.

Outro aspecto importante a ressaltar é que a produção das peças é feita a partir do velo da ovelha. Ou seja, as artesãs iniciam seus trabalhos desde o preparo da lã, como nas origens da técnica. Assim, após a tosquia da ovelha, o velo, produto direto, é lavado com uso de detergente neutro; secado; aberto manualmente; cardado; fiado na roca; tingido com produtos naturais e depois, confeccionadas as peças. A não utilização de equipamentos industriais e maquinários na produção das peças mostra-se como uma característica específica nos grupos de artesanato pesquisados. Através de trabalhos com o Serviço Brasileiro de Apoio às Micro e 
Pequenas Empresas (SEBRAE) e apresentações dos produtos em feiras foram conquistadas diversas premiações, justamente pelo preparo da lã de forma natural e manual, além da própria técnica empregada.

\begin{abstract}
Nós estamos buscando resgatar isso, porque com certeza isso vai voltar, e está voltando, já tem um bom tempo que está voltando. Hoje, fora aqui de Jaguarão, em outros países, lã é uma coisa muito cara, sabe, a lã natural mesmo ela é muito cara, e ela é terapêutica, ela tem que vir com todo o processo, o mínimo possível industrial, então, eles estão buscando isso aí. (W.A.F., integrante do grupo As Cardadeiras, vinculado à economia solidária, entrevistada no dia 16 de setembro de 2017).
\end{abstract}

O processo de trabalho da lã demonstra-se um bem cultural, não apenas pelo meio de produção das peça, mas principalmente a preocupação das artesãs com a continuação das memórias de suas antepassadas de forma mais próxima possível, reconstituindo cada um de seus processos como fazia-se antes da modernização. Observa-se que tal preocupação reforça o apego sentimental das mesmas ao realizarem o ofício, e também o torna peculiar, agregando valor aos produtos.

A propagação da técnica entre as novas gerações é um importante método de preservála e manter sua funcionalidade no contexto atual. $\mathrm{O}$ relato da depoente indica as variações que a técnica sofre ao se adequar à rotina moderna das novas gerações. Aplicam-se novos conceitos, novas tendências, novos métodos e mesmo novas significações às memórias, a fim de mantê-la não apenas como objeto de recordação dos antepassados, mas como parte cultural dos povos ainda integrante do seu modo de vida, o que é fundamental para sua preservação e manutenção da identidade cultural, como apresenta Candau (2011).

Durante a pesquisa, algumas ameaças à preservação da técnica foram identificadas pelas artesãs entrevistadas. Os principais aspectos levantados têm relação com o baixo incentivo do setor público, a ausência de uma infraestrutura para exposição das peças, o baixo poder aquisitivo da população local, e as barreiras instituídas pela modernização e industrialização dos meios de produção, que competem com as peças na comercialização.

Desse modo, nota-se nos fluxos turísticos que procuram o destino, potenciais consumidores para as peças confeccionadas em tecelagem, em razão do segmento de compras na zona franca de Rio Branco. Assim, percebe-se a viabilidade de sua comercialização como souvenir da fronteira.

As artesãs citaram ainda a intenção de estimular os ovinocultores a confeccionarem as peças em tecelagem e Jacquard diretamente, a partir da lã produzida, e comercializarem-nas 
como produto final. Desse modo a renda gerada seria maior e a técnica seria passada à mais pessoas.

[...] incentivar que os produtores continuem produzindo as ovelhas, registrar as ovelhas para ter uma lã de qualidade, não é questão de quantidade, é mais é qualidade, grupos pequenos e lotes grandes e aí a gente faz todo aquele processo, desde quando a ovelha nasce e começa a cuidar dela a produzir a lã e aí fazem a tosquia e aí nós fazemos a lavagem e aí entram por exemplo as artesãs até o próprio produtor mesmo ele pode ser um artesão se ele quiser fazer com que isso ai faça parte do grupo da agricultura familiar que aí todos os componentes da família faz esse processo de fazer a tosquia, de lavar, de cardar, fiar e produzir as peças porque nas propriedades seria o foco maior que teria um retorno era eles produzirem peças tipo exportação e não assim: "eu produzo a ovelha ai manda para a Cooperativa e a Cooperativa manda para a fábrica [...] (W.A.F., integrante do grupo As Cardadeiras, vinculado à economia solidária, entrevistada no dia 16 de setembro de 2017).

Assim, a confecção de peças com a lã produzida pode ser trabalhada no próprio local de criação dos ovinos. Desse modo os produtores recebem uma renda maior, além de expandirem sua linha de produção e repassarem a técnica novamente.

Igualmente, a criação de ovinos como forma de produção de lã para a confecção das peças pelas artesãs também é uma possibilidade, como no caso a seguir relatado:

Nós temos uma colega nossa que ela foi a Farroupilha e eles produzem as ovelhas, são produtores mesmo, [...] ela sempre tira foto dos cordeirinhos quando nascem. Ela tem a Ideal 1 e tem a Merino. Só tem em Piratini. Então, ela produz tudinho, então são todos selecionados, todos têm numeração, aí eles produzem as peças e as peças que vão para venda. Ela não vende a ovelha, ela não vende a lã, ela vende somente as peças, ela faz exposição na "Gaúcho e Prenda", ela tem ali, então são peças únicas e a pessoa não vai encontrar peças iguais, então se agrega bastante valor, quando se tornam assim, peças únicas, agrega bastante valor [...]. (W.A.F. no dia 16 de setembro de 2017).

Quando comercializadas, as peças, criadas a partir da expressão da artesã, através de uma técnica incomum e herdada por mulheres, de geração a geração, as peças em tecelagem adquirem uma maior valorização. Apesar de demandar maior tempo e dedicação para confecção, as peças abarcam um valor maior.

O nosso carro chefe seria por exemplo seriam as peças confeccionadas com a lã, porque nós não temos o intuito de vender a lã cardada, a lã fiada, porque não tem um retorno, não tem muito retorno, sabe, então o produto que a gente trabalha é justamente para vender a peça final, que são cobertores, juanas, palas, blusões, até produtos, por exemplo, de casa, design de casa [...]. (W.A.F., integrante do grupo As Cardadeiras, vinculado à economia solidária, entrevistada no dia 16 de setembro de 2017).

\footnotetext{
${ }^{4}$ Gaúcho e Prenda corresponde a uma loja de artigos e vestuário típicos da cultura gaúcha, localizada na cidade de Pelotas/RS.
} 
Considerando a quantia arrecadada com a venda direta da lã, e o valor ganho na comercialização das peças confeccionadas a partir da tecelagem, cuja vantagem econômica é notável, os produtores aumentariam sua renda a partir dos trabalhos artesanais. Como as artesãs relataram, o processo de preparo da lã compensa seu lucro apenas quando utilizado na tecelagem, tornando a venda dos novelos uma prática de baixo retorno.

Entretanto, na zona rural do município, onde encontram-se maiores números de tecelões e ovinocultores, é notória a resistência ao setor turístico, como já citado, justificandose também pelo receio quanto às ameaças à identidade cultural local em decorrência do contato com os turistas. Percebendo a possível descaracterização de sua bagagem cultural ou sua modificação em razão dos fluxos culturais advindos do turismo, os autóctones rejeitam as propostas do setor, a fim de preservar suas tradições e o modo de vida típico da região o mais autêntico possível.

Por outro lado, o turismo, quando desenvolvido de forma sustentável, e seus agentes instruídos de forma a minimizar seus impactos negativos, mostra-se como propulsor econômico no destino, agindo também como forma de valorizar, e consequentemente, auxiliando na preservação dos bens culturais, e proporcionando melhoras nos aspectos sociais. Dessa forma, inicialmente, deve-se propor formas de incluir esses moradores no circulo econômico do turismo, e assim permitir que sua distribuição chegue também à essas regiões do município, sem danificar sua identidade.

Por conta da zona franca, estabelecida na fronteira com a cidade de Rio Branco Uruguai, o município de Jaguarão recebe, em maior número, um fluxo turístico destinado ao segmento de compras. Assim, percebe-se nesses turistas clientes em potencial para a comercialização das peças em lã natural, e até mesmo sua confecção como souvenir.

A possibilidade de comercialização de peças confeccionadas em lã natural como souvenir, termo entendido como símbolo para evocação de lembranças, demonstra uma maneira de inserir não apenas os artesãos no circulo econômico do turismo, como também os produtores de lã, que fornecem a matéria-prima desse artesanato. Assim, o contato com os fluxos turísticos é restrito, evitando alguns riscos à identidade local, e o modo de vida dos autóctones é valorizado, com a venda do produto final de suas tradições e estilo de vida: o souvenir em lã natural. 


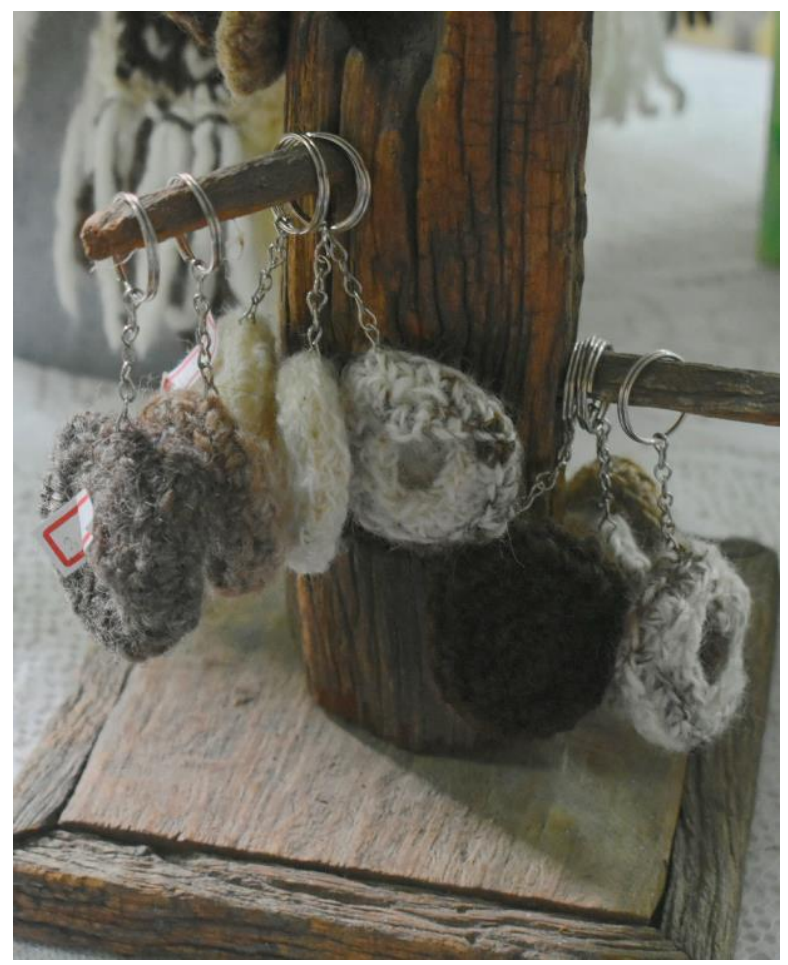

Figura 3 - Chaveiros no formato de boinas confeccionados em crochê.

Fonte: Acervo da autora (2018).

Demonstrando as características históricas e culturais do destino, as peças confeccionadas em lã natural contribui para a manutenção da técnica enquanto bem cultural e memória, uma vez que sua produção reflete uma atividade ainda presente na rotina dos moradores locais, dando visibilidade ao conjunto cultural de Jaguarão. Consequentemente, a valorização de seu modo de vida, sem interferir diretamente na cadeia geral de produção do artesanato, evita a perda das identidades envolvidas no processo.

Ficou evidente, ao longo da pesquisa, que a possibilidade de comercialização de souvenir e contato com o turista é dificultado, principalmente, pela ausência de mediação entre as artesãs e o fluxo turístico. A falta de visibilidade e de divulgação das peças confeccionadas e as dificuldades apresentadas para estabelecer um ponto de comercialização na atual sede do grupo, cedida pela prefeitura, e localizada no interior do prédio da Secretaria do Desenvolvimento Econômico, tornam inviável o contato.

Desse modo, a inserção da atividade turística para as artesãs e no meio rural se daria indiretamente, permitindo a preservação do modo de vida dos moradores, comercializando apenas o produto final de suas lidas campeiras. A circulação de renda aumenta a partir do turismo, bem como a visibilidade e a valorização dos fazeres culturais. A preocupação dos 
moradores do meio rural com a modificação da identidade seria também minimizada, uma vez que sua comercialização não afetaria o desempenho de suas atividades rotineiras.

\section{Considerações finais}

A construção do estudo proporcionou novas perspectivas sobre a técnica artesanal de tecelagem em lã natural enquanto identidade, memória e bem cultural da população local de Jaguarão. Como o Jacquard, que mostra-se uma técnica característica do município, a tecelagem em lã natural representam uma memória transmitida entre as gerações nas famílias jaguarenses, em específico na zona rural, e que ao acompanhar os fluxos culturais e a modernização, sem perder sua essência, permanece ativo no cotidiano dos moradores da região.

Assim, demonstrou-se suas relações com o desenvolvimento da atividade turística na zona rural do município e seus impactos socioculturais. As características culturais, impressas nas tramas do artesanato em lã natural representam memórias dos tecelões do município e as marcas da ovinocultura na constituição de sua bagagem cultural.

Analisando o souvenir em peças de tecelagem em lã natural como proposta para a inserção dos artesãos e ovinocultores jaguarenses na circulação de renda gerada através do turismo, percebeu-se seu emprego como uma forma de ampliar a visibilidade da técnica como bem cultural do município e valorizar as memórias e o modo de vida local. Dessa forma, auxiliaria em sua manutenção e propagação entre os autóctones. Sem contato direto com os turistas, as ameaças trazidas pela atividade sobre a identidade cultural dos moradores da zona rural seriam minimizadas, e ainda assim, seria possível a geração de renda a partir do turismo.

Com o fluxo de turistas do segmento de compras, direcionado à zona franca de Rio Branco, notam-se oportunidades de comercialização das peças como souvenir da fronteira, uma vez que estas representam uma característica comum a ambos os municípios. Dessa forma, os artesãos de lã natural, que tem encontrado barreiras no mercado, decorrentes do baixo poder aquisitivo local e da concorrência com a produção industrial, encontra uma possibilidade de geração de renda.

A pesquisa, realizada junto às artesãs de lã natural da Associação Municipal dos Artesãos e do grupo "As Cardadeiras", vinculado à Economia Solidária de Jaguarão, proporcionou a compreensão das técnicas artesanais como bens culturais e memórias, constituintes de sua identidade. Dessa forma, a percepção de sua importância cultural e social para os artesãos demonstrou a necessidade da busca de alternativas sustentáveis para sua inserção no setor turístico do destino. 
Os dados levantados durante a realização do estudo representam apenas uma parte dos tecelões do município, localizados na região urbana, os quais se tinha conhecimento. Entretanto, para uma análise mais aprofundada do tema, é necessária a ampliação da pesquisa, contatando artesãos e produtores do meio rural, verificando também suas posições quanto ao desenvolvimento do turismo na região.

\section{Referências}

BANDUCCI JÚNIOR, Álvaro; BARRETO, Margarita (Org.). Turismo e identidade local: uma visão antropológica. Campinas: Papirus, 2006.

CANDAU, Joel. Memória e identidade. São Paulo: Contexto, 2011.

CASTRO, Amanda Mota Angelo; BECKER, Márcia Regina; EGGERT, Edla. Técnica e Arte: Trabalho artesanal produzido por mulheres e sua (in)visibilidade social. In: VIII CONGRESSO IBEROAMERICANO DE CIÊNCIA, TECNOLOGIA E GÊNERO, 2010, Curitiba. Anais... . Curitiba: UTFPR, 2010, p. 1-9. Disponível em: $<$ https://docplayer.com.br/10705337-Tecnica-e-arte-trabalho-artesanal-produzidopormulheres-e-sua-in-visibilidade-social.html>. Acesso em: 21 set. 2018.

COSTA, Luciana de Castro Neves; GASTAL, Suzana de Araújo. Turismo e paisagem cultural: para Pensar o Transfronteiriço. In: IV SEMINÁRIO DE PESQUISA EM TURISMO DO MERCOSUL: SABERES E FAZERES NO TURISMO: INTERFACES. 2010, Caxias do Sul. Anais... Caxias do Sul: Universidade de Caxias do Sul, 2010. p. 1-14.

DE PAULA, Tauana Macedo; MECCA, Marlei Salete. Significados do souvenir turístico atribuidos pelos turistas do passeio de trem "maria fumaça", estação de Bento Gonçalves/RS. Turismo - Visão e Ação, [s.1.], v. 18, n. 2, p.378-404, maio 2016. Disponível em: <https://siaiap32.univali.br/seer/index.php/rtva/article/view/8872>. Acesso em: 18 nov. 2018.

ESCALONA, Emilia García. De la relíquia al souvenir. Revista de Filología Románica, Madrid, p. 399-408, 2006. Disponível em: <http://revistas.ucm.es/index.php/RFRM/article/view/RFRM0606220399A >. Acesso em: 18 nov. 2018.

GIL, Antonio Carlos. Métodos e técnicas de pesquisa social. $6^{\mathbf{a}}$ edição, São Paulo: Atlas, 2008.

HORODYSKI, G.; MANOSSO, F.; GÂNDARA, J. M. A pesquisa narrativa na investigação das experiências turísticas relacionadas ao consumo de souvenirs: uma abordagem fenomenológica. Revista Turismo em Análise, v. 25, n. 1, p. 203-230, 30 abr. 2014. Disponível em: <https://www.revistas.usp.br/rta/article/view/80713>. Acesso em: 18 nov. 2018.

INSTITUTO BRASILEIRO DE GEOGRAFIA E ESTATÍSTICA. Produção Pecuária Municipal. Disponível em: <https://cidades.ibge.gov.br/brasil/rs/pesquisa/18/16459>. Acesso em: 18 nov. 2018. 
KRIPPENDORF, Jost. Sociologia do turismo: para uma nova compreensão do lazer e das viagens. São Paulo: Aleph, 2009.

OLIVEIRA, José Carlos Franco de. A ovinocultura como prática pedagógica e agregação de valores. In: PARANÁ. Secretaria de Estado da Educação. Superintendência de Educação. O professor PDE e os desafios da escola pública paranaense, 2012. Curitiba: SEED/PR., 2014. V.1. (Cadernos PDE). Disponível em:

<www.gestaoescolar.diaadia.pr.gov.br/modules/conteudo/conteudo.php?conteudo=20>. Acesso em 20 nov. 2018.

PANOSSO NETTO, Alexandre. O que é turismo. São Paulo: Brasiliense, 2010.

SILVA, Diego Rodrigues da; ANNA, Paulo Afranio Sant'. Turismo e confronto com a identidade cultural: impactos psicossociais da atividade turística em Diamantina- MG. Revista Turismo em Análise, [s.1.], v. 25, n. 3, p.649-676, dez. 2014. Disponível em: <https://www.revistas.usp.br/rta/article/download/89485/pdf/>. Acesso em: 08 nov. 2018.

VIANA, João Garibaldi Almeida; WAQUIL, Paulo Dabdab; SPOHR, Gabriela. Evolução histórica da ovinocultura no rio grande do sul: comportamento do rebanho ovino e produção de lã de 1980 a 2007. Revista Extensão Rural, Santa Maria, v. 20, jul./dez 2010. Disponível em: 〈https://periodicos.ufsm.br/extensaorural/article/view/5548>. Acesso em: 29 ago. 2018.

WILLIAMS, Raymond. Cultura. São Paulo: Paz e Terra, 2011. 